\title{
VISITOR FLOW OF CULTURALLY IMPORTANT AREAS: AN AHP PERCEPTION ON THE TRAIL SELECTION IN SRIPADA MOUNTAIN AREA OF SRI LANKA
}

\begin{abstract}
A culturally important area is an asset for a country. While the importance is more on local people, global importance get strengthened when it becomes a world heritage. The Sripada mountain is one of the culturally important areas located in the world heritage site, Peak Wilderness in Sri Lanka. It may be the only mountain that four major religions venerate and believe there is a link according to their religion with their own beliefs and practices. There are many trails to climb the Sripada mountain. The purpose of this paper is to examine the relationship between the selection of a trail and its consequences to the sustainability in the Sripada mountain region using the Analytic Hierarchy Process (AHP). This research mainly focuses on discussing the importance of factors governing the flow of visitors along trails. This research uses two approaches to rank trails to find out the influence of factors on trail selection using AHP analysis in order to make future scenarios for sustainable environment decision making. The two approaches known as data-directed and user-directed were used in this research. The data directed approach uses geographical explanations and AHP whereas the user directed approach uses questionnaire only for experts and AHP on trail ranking hence the visitor flow.
\end{abstract}

Keywords: trails, visitor flow, geographical analysis. 